\title{
DOES VITAMIN D STATUS CORRELATE WITH CARDIOMETABOLIC RISK FACTORS IN ADULTS WITH GROWTH HORMONE DEFICIENCY?
}

\author{
Ivayla Uzunova1 ${ }^{1}$, Georgi Kirilov', Sabina Zacharieva', Naydenka Zlatareva², Krassimir Kalinov ${ }^{3}$
}

1Department of Hypothalamic, Pituitary, Adrenal and Gonadal Diseases, Clinical Centre of Endocrinology and Gerontology, Medical University - Sofia 2University Hospital "Tsaritsa Yoanna - ISUL”, Medical University - Sofia

${ }^{3}$ New Bulgarian University, Sofia, Bulgaria

2 Zdrave Str., Sofia, Bulgaria; e-mail: dr_uzunova@yahoo.com

Apart from being individually associated with cardiometabolic health, Vitamin $D$ and growth hormone/insulin-like growth factor-1 (GH/IGF-1) axis are reported to interplay, with a positive correlation between IGF-1 and 25-hydroxyvitamin $D(25(\mathrm{OH}) D)$. These findings raise questions about the role of vitamin $D$ for the adverse cardiovascular (CV) risk profile in hyposomatotropism.

\section{Aim of the research}

The aim of the study was to investigate the association between 25(OH)D and metabolic syndrome (MetS), its components and other surrogate markers of $\mathrm{CV}$ risk.

\section{Patients and methods}

This cross-sectional study included $\mathbf{1 2 9}$ adults (70 males, $42.1 \pm 16.6$ years) with GHD [childhood-onset GHD (COGHD): $n=54$ ]. Each subject underwent routine biochemical blood testing, anthropometric (body mass index, waist circumference, waist-to-hip ratio, percent body fat, visceral fat area, skeletal muscle mass) and blood pressure measurements. Other CV risk markers were examined in a subsample of the initial population - highsensitivity C-reactive protein, adiponectin and asymmetric dimethylarginine $(n=88)$; intima-media thickness of carotid arteries $(n=44)$. Total serum 25(OH)D was used to assess vitamin $D$ status and was measured by electro-chemiluminescence binding assay (COBAS, Roche Diagnostics International Ltd; analytical sensitivity - $4.01 \mathrm{ng} / \mathrm{ml}$; within-run and intermediate precisions $-\leq 6.5 \%$ and $\leq 11.5 \%$, respectively) Vitamin D status and GHD were defined according to the Endocrine Society Clinical Practice Guideline recommendations. MetS was scored by the National Cholesterol Education Program - Adult Treatment Panel III criteria. Statistical analysis was performed using SPSS for Windows, version 23.0.

Results

Approximately a quarter of the patients $(n=32,16$ men, 6 COGHD) fulfilled the NCEP-ATPIII criteria for MetS. Those diagnosed with MetS demonstrated significantly lower 25(OH)D levels compared with the subjects without MetS $(11.8 \pm 4.5 \mathrm{ng} / \mathrm{ml}$ vs. $16.3 \pm 8.1 \mathrm{ng} / \mathrm{ml}, \mathrm{p}<0.0001)$ (Figure 1).

\section{5(OH)D levels (ng/ml)}

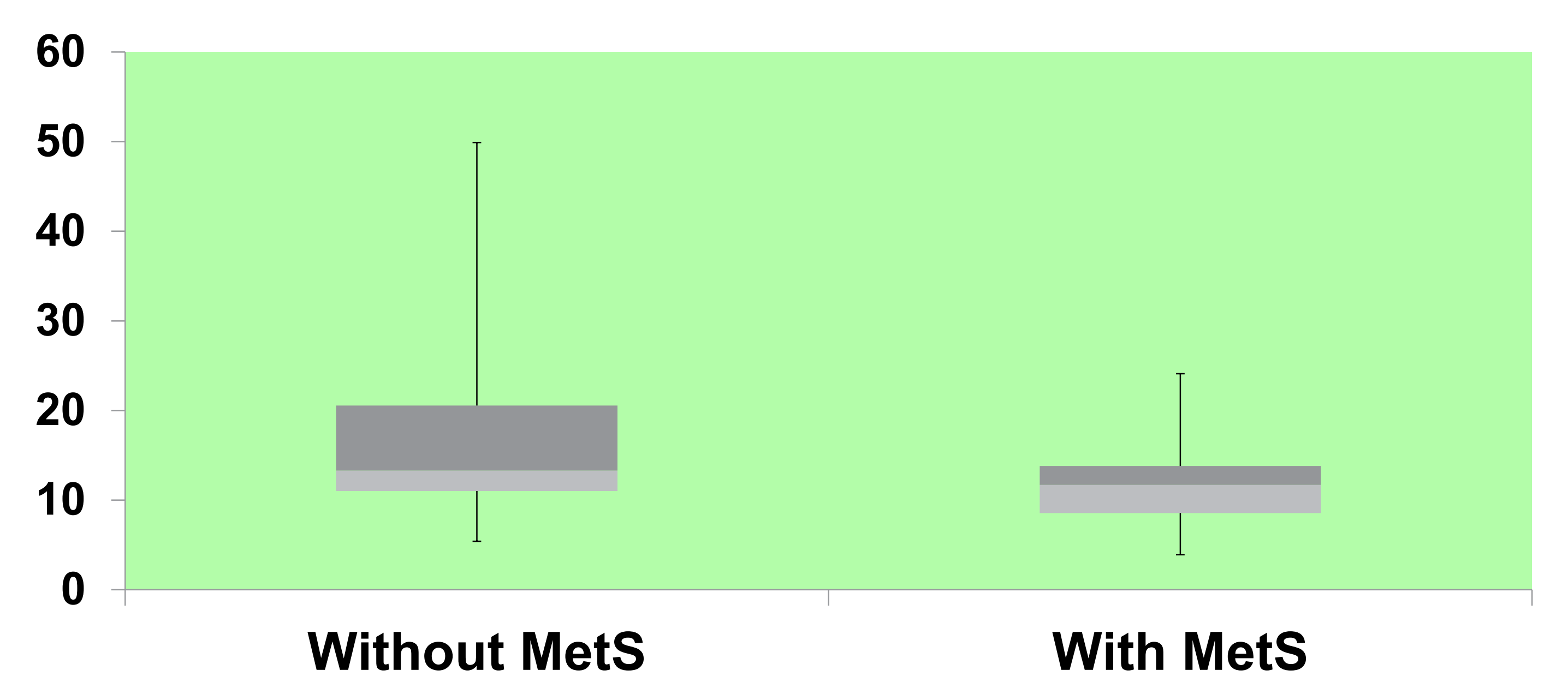

Figure $125(\mathrm{OH}) \mathrm{D}$ levels in GHD patients with MetS ( $n=32)$ and without MetS $(n=97), p<0.0001$

Further on, we analyzed the association between vitamin $D$ status (adequate vs. insufficient and deficient, i.e. $25(\mathrm{OH}) \mathrm{D}$ levels $\geq 30 \mathrm{ng} / \mathrm{ml}$ vs. $<$ $30 \mathrm{ng} / \mathrm{ml}$ ) and the individual components of the MetS as well as some other biochemical and anthropometric factors (normal vs. abnormal values) proved to affect CV risk. (Table 1)
Inadequate 25(OH)D concentrations were associated only with higher prevalence of increased WC and waist-to-hip ratio. All these parameters were also analyzed as continuous variables. Serum 25(OH)D correlated negatively and weakly with systolic blood pressure and anthropometric indices - BMI, WC, PBF and VFA.

\begin{tabular}{|l|c|c|c|}
\hline \multirow{2}{*}{ Variable } & \multirow{2}{*}{$\begin{array}{c}\text { Fisher's Exact Test } \\
\text { p-value }\end{array}$} & \multicolumn{2}{|c|}{ Correlation analysis } \\
\cline { 3 - 4 } & 0.732 & -0.069 & pearson Coefficient \\
\hline Total cholesterol & 0.152 & 0.076 & 0.435 \\
\hline HDL-cholesterol & 0.862 & -0.051 & 0.392 \\
\hline LDL-cholesterol & 0.485 & -0.125 & 0.579 \\
\hline Triglycerides & 1.000 & -0.121 & 0.157 \\
\hline Fasting Glucose & 0.683 & -0.101 & 0.174 \\
\hline Uric acid & 1.000 & 0.106 & 0.258 \\
\hline Fasting Insulin & 0.681 & 0.057 & 0.265 \\
\hline HOMA-IR & 0.683 & -0.179 & 0.553 \\
\hline Systolic Blood Pressure & 0.869 & -0.040 & $0.042^{*}$ \\
\hline Diastolic Blood Pressure & 0.294 & -0.197 & 0.650 \\
\hline Body Mass Index & $0.010^{*}$ & -0.356 & $0.026^{*}$ \\
\hline Waist Circumference & $0.033^{*}$ & -0.193 & $<0.0001^{*}$ \\
\hline Waist/Hip Ratio & 0.173 & -0.228 & 0.052 \\
\hline Percent Body Fat & 0.060 & -0.308 & $0.033^{*}$ \\
\hline Visceral Fat Area & 0.103 & 0.082 & $0.004^{*}$ \\
\hline Skeletal Muscle Mass & & & 0.447 \\
\hline
\end{tabular}

Table 1 Association between 25(OH)D levels and some biochemical and anthropometric markers known to affect cardiovascular risk

*Statistically significant $p$-value $(p<0.05)$

Correlation analysis of 25(OH)D levels was also performed including some other markers related to atherogenesis, vascular inflammation and endothelial function, such as hs-CRP, adiponectin, ADMA and IMT (Table 2). No significant associations were observed.

\begin{tabular}{|l|c|c|}
\hline Variable & Pearson Coefficient & p-value \\
\hline hs C-reactive protein & -0.134 & 0.229 \\
\hline Adiponectin & 0.069 & 0.521 \\
\hline Asymmetric dimethylarginine & -0.044 & 0.689 \\
\hline Intima-media thickness & -0.297 & 0.053 \\
\hline
\end{tabular}

Table 2 Correlation between 25(OH)D levels and makers related to atherogenesis, vascular inflammation and endothelial function

\section{Conclusion}

The severe impairment of vitamin D status in hyposomatotropism and its association with adiposity and BP warrant 25(OH)D testing in GHD patients. Although the normalization of the vitamin D status has not been proven to improve CV outcomes in general population, it might have beneficial effects in GHD subjects, especially in those with obesity or hypertension. Patients with a combination of GHD, hypovitaminosis $D$ and MetS show an adverse $C V$ risk profile and need more active therapeutic care.

References:

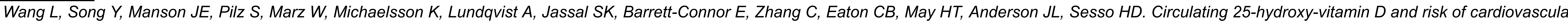
disease: a meta-analysis of prospective studies. Circ Cardiovasc Qual Outcomes 2012; 5(6): 819-29 five years: results from a national, population-based prospective study (The Australian Diabetes, Obesity and Lifestyle Study: AusDiab). Molitch ME, Clemmons DR, Malozowski S, Merriam GR, Vance ML; Endocrine Society.

Metab 2011:96(6): 1587-609

Executive Summary of The Thir

Holick MF, Binkley NC, Bischoft-

Ferrari HA, Gordon CM, Hanley DA, Heaney RP, Murad MH, Weaver CM; Endocrine Society. Evaluation, treatment, and prevention of vitamin D deficiency: an Endocrine Society clinical practice guideline. J. Clin. Endocrinol. Metab 2011; 96(7): 1911-30 